\title{
H63D Syndrome: A rare clinical phenotype caused by a homozygous mutation of HFE gene H63D
}

Dr. Carolina Diamandis ${ }^{1}$, Dr. David Seideman ${ }^{1}$, Jacob S. Adams ${ }^{2}$, Dr. Marianne

Kaufmann ${ }^{2}$, and Alexander Davis, $\mathrm{MD}^{1}$

${ }^{1}$ Lazar Clinic Group

${ }^{2}$ H63D Syndrome Research Consortium

May 3, 2021

\begin{abstract}
H63D syndrome is a unique phenotype (clinical picture) of a homozygous mutation of the HFE gene H63D, which is otherwise known to cause at most mild classical hemochromatosis. H63D syndrome is associated with iron overload in the body (especially in the brain, heart, liver, skin and male gonads), but in the form of non-transferrin bound iron (NTBI), not as ferritin. It is an incurable multi-organ disease, leading to permanent disability, which can only be influenced by early diagnosis and a very careful reduction of iron intake (under constant monitoring) as early as in childhood and youth. Our goal was to better highlight the characteristic symptoms of this rare disease to further reduce the risk of missing diagnosing this dangerous condition correctly, even on a primary care level.
\end{abstract}

\section{Hosted file}

H63D Syndrome - Study.pdf available at https://authorea.com/users/410930/articles/520150h63d-syndrome-a-rare-clinical-phenotype-caused-by-a-homozygous-mutation-of-hfe-gene-h63d 